\title{
Cytogenetic Abnormalities in Multiple Myeloma Patients at a Tertiary Healthcare Center in India
}

\author{
Perumal Govindasamy ${ }^{1}$, Prabu Pandurangan², Anil Tarigopula ${ }^{1}$, Rama Mani ${ }^{1}$, \\ Chandra R Samuel ${ }^{3 *}$
}

\begin{abstract}
Objective: Multiple myeloma (MM) is a clinically and genetically heterogeneous plasma cell neoplasm. The prognosis of MM patients is dependent on several factors including the patient's age, the stage of disease and genetic alterations. This study aimed to determine the frequency of common chromosomal abnormalities and their significance in MM patients referred to a tertiary healthcare center in India. Methods: Fluorescence in situ hybridization on interphase nuclei from bone marrow cells using seven MM-specific probes for recurrent aberrations was performed in a total of 215 newly diagnosed patients. Results: Chromosomal abnormalities were detected in 161 (74.9\%) MM patients in this study. The most frequent aberration was trisomy(ies) involving only gain of chromosomes in $48(22.3 \%)$ cases. A translocation involving the IGH gene alone or accompanied by trisomy(ies) or by monosomy $13 / 13 q$ deletion or by both was registered in $80(37.2 \%)$ patients. Atypical patterns such as a deletion of the IGH variable segment (IGHv) on the derivative chromosome 14 or on the native (normal) chromosome 14, biallelic deletion of IGHv, deletion of the IGH constant segment on the rearranged chromosome14 and extra fusions were noticed in 21 (9.8\%) patients with an IGH rearrangement. Monosomy 13/deletion 13q was identified singly or as part of a complex karyotype in 74 patients (34.4\%). Clonal heterogeneity and additional abnormalities including TP53 deletion and monosomies of chromosomes 4, 9, 14 and 16 were recorded in $18.6 \%$ and $16.3 \%$ of patients respectively. Patients with abnormalities exhibited plasmacytosis, reduced hemoglobin value and high level of $\beta 2$-microglobulin. Conclusions: A lower median age and a low frequency of IGH translocations particularly $\mathrm{t}(11 ; 14)$ and chromosome 13 abnormalities suggest ethnic diversity. Further investigations on genetic alterations including IGH deletions will contribute to improved insights into the biology of myeloma disease, risk stratification and patient management.
\end{abstract}

Keywords: Clonal heterogeneity- interphase FISH- IGH deletion- multiple myeloma

Asian Pac J Cancer Prev, 20 (1), 235-241

\section{Introduction}

Multiple myeloma (MM) is a heterogeneous hematologic malignancy which is characterized by an uncontrolled proliferation of antibody-secreting plasma cells within the bone marrow (Talley et al., 2015; Fairfield et al., 2016). It usually evolves from the premalignant monoclonal gammopathy of unknown significance (MGUS) and then progresses through smouldering multiple myeloma (SMM) to end-stage MM. In 2014, the International Myeloma Working Group (IMWG) updated the diagnostic criteria for MM to include specific biomarkers (clonal bone marrow plasma cells $\geq 60 \%$, serum free light chain ratio $\geq 100$, and $>1$ focal lesion) to existing markers of end-organ damage (hypercalcemia, renal insufficiency, anemia and bone lesions) (Rajkumar et al., 2014). The Durie-Salmon staging system which specified tumor burden for staging MM was substituted by the International Staging System (ISS) based on the level of serum $\beta 2$ microglobulin and albumin (Griepp et al., 2005). This system was then updated to the Revised International Staging System (R-ISS) which utilized high-risk chromosomal abnormalities (CA) detected by interphase fluorescence in situ hybridization (iFISH) and lactate dehydrogenase with ISS score for risk stratification of MM patients (Palumbo et al., 2015; Rajkumar and Kumar, 2016).

The primary cytogenetic abnormalities comprise hyperdiploidy involving trisomy of the odd numbered chromosomes 3, 5, 7, 9, 11, 15, 19 and 21, and reciprocal translocations involving the immunoglobin heavy chain (IGH) gene at 14q32 leading to increased transcription of the genes FGFR3 and MMSET (4p16.3), CCND1 (11q13), CCND3 (6p21), MAF (16q23) and MAFB (20q11). Secondary chromosomal aberrations including MYC translocations, chromosome 13 aberrations (monosomy

${ }^{1}$ Department of Centralised Molecular Diagnostics, ${ }^{2}$ Department of Haematology, Apollo Hospitals, Chennai-6, ${ }^{3}$ Department of Genetics, Dr. ALMPGIBMS, University of Madras, Chennai-113, Tamil Nadu, India. *For Correspondence: nchandrarsamuel@gmail.com 
or deletion of $13 q 14$ ), deletion of $17 p$ specifically TP53 and/or chromosome 1 aberrations (deletions in $1 p$ and amplification in 1q) are associated with shorter survival, aggressive disease, and the presence of extramedullary disease (Bergsagel and Kueh1, 2005; Nadiminti et al., 2013; Prideaux et al., 2014; Rajan and Rajkumar, 2015). Refinement of the prognostic markers in MM through advanced genetic technologies will eventually lead to enhancement of the efficacy of the therapeutic approaches (Hanbali et al., 2017; Sommaluan et al., 2017). Conventional G-banded metaphase analysis provides a global view of the chromosomal changes at the cellular level, albeit at a low resolution while interphase FISH improved the detection of these abnormalities by the use of region-specific probes and facilitated analysis on a cell-by-cell basis (Nilsson et al., 2003; Gutierrez et al., 2007). It is now recommended to include conventional cytogenetic analysis together with iFISH in the initial diagnostic work-up for MM patients (Li et al., 2016; Sommaluan et al., 2017). Published reports on cytogenetic abnormalities in MM are scarce in patients of South Asian descent (Amare et al., 2016; Ashok et al., 2017; Sommaluan et al., 2017). The present study was aimed to evaluate the frequency of cytogenetic abnormalities and to determine their clinico-pathological significance in MM patients at a tertiary referral centre in South India.

\section{Materials and Methods}

\section{Patients}

A total of 215 (146 male and 69 female) untreated multiple myeloma patients, aged between 30 and 87 years, were referred to the Department of Centralised Molecular Diagnostics, Apollo Hospitals, Chennai-6 during the period July 2012 to December 2015. The criteria for diagnosis of MM was based on revised IMWG guidelines (Rajkumar et al., 2014). This study was approved by the Ethics Committee of Apollo Hospitals, Chennai. After written informed consent was obtained from the patients, detailed case history was collected and heparinized bone marrow samples were collected with the help of clinicians.

\section{Interphase fluorescence in situ hybridization (iFISH)}

The iFISH protocol was performed according to manufacturer's specifications on unsorted bone marrow cells/ enriched plasma cells (if plasma cells less than 50\%) using RosetteSep human multiple myeloma enrichment cocktail (STEMCELL Technologies, Vancouver, Canada) followed by Ficoll-Paque plus density gradient centrifugation. Multiple myeloma panel comprised of the following seven commercially available Vysis probes (Abbott Molecular, USA) - the LSI IGH dual-color break-apart probe to detect IGH rearrangement followed by the dual-color, dual-fusion translocation probes LSI IGH/FGFR3, LSI IGH/CCND1 XT and LSI IGH/MAF to identify $\mathrm{t}(4 ; 14)(\mathrm{p} 16.3 ; \mathrm{q} 32.3), \mathrm{t}(11 ; 14)(\mathrm{q} 13 ; \mathrm{q} 32)$ and $\mathrm{t}(14: 16)(\mathrm{q} 32 ; 23)$ respectively; the CEP 9 probe to enumerate chromosome 9; LSI D13S319 (13q14.3)/ LSI $13 \mathrm{q} 34$ probe for monosomy 13/deletion 13q and LSI TP53/CEP17 probe for monosomy 17/ deletion 17p (TP53 gene).
For every case, a total of 300 interphase nuclei were scored for each probe under oil immersion lens for the presence of signals using different filters in Olympus BX-51 microscope (Olympus, Tokyo, Japan). The images were captured and analysed with the Applied Spectral Imaging Systems software (FISH View version 6.0). The cut-off level for all the probes was 5\% (Yuregir et al., 2009).

\section{Results}

The majority of the patients were aged between 50 and 65 years (median 58 years) and the chief complaints were bone pain and fatigue. They showed reduced hemoglobin value and high levels of creatinine and $\beta 2$-microglobulin. Immunofixation electrophoresis revealed monoclonal IgG in $55.8 \%$, IgA in $19.1 \%$ and $\operatorname{IgM}$ in $1.9 \%$. Light chain only disease was present in $5.1 \%$ of patients (Table 1). At diagnosis 143 patients $(66.5 \%)$ were in ISS stage III. The majority (77.2\%) belonged to the states of Tamil Nadu, West Bengal and Assam while 8.4\% were from outside India. Interphase FISH (iFISH) revealed chromosomal abnormalities in $161(74.9 \%)$ MM patients and based on the type of abnormalities these patients were classified into eight groups (Table 2). The most frequent group was trisomy(ies) which comprised of only a gain of one, two or more chromosomes and was recorded in 48 (22.3\%) patients. The most commonly observed gain (trisomy and tetrasomy) (partial or complete) was that of chromosome 9 (63.6\%), followed by those of chromosomes $11(44.6 \%)$, $16(16.4 \%), 4(12.7 \%), 17(11.8 \%), 14(8.2 \%)$ and 13 (6.4\%) (Figure 1a-h).

A translocation involving IGH locus alone was seen in 14 cases while it was accompanied by monosomy

Table 1. Demographic and Laboratory Characteristics of Multiple Myeloma Patients $(\mathrm{N}=215)$

\begin{tabular}{|c|c|}
\hline Characteristics & No. of Patients \\
\hline Sex (male/ female) & $146 / 69$ \\
\hline Age $(<50 / 50-65 />65)$ & $49 / 113 / 53$ \\
\hline $\begin{array}{l}\text { Education (Illiterate/ Primary/ Higher } \\
\text { secondary/ UG and above) }\end{array}$ & $7 / 112 / 23 / 73$ \\
\hline $\begin{array}{l}\text { Occupation (Clerical/ Skilled/ Agriculture/ } \\
\text { Others*) }\end{array}$ & $86 / 30 / 15 / 84$ \\
\hline Hemoglobulin $(<8.5 / 8.5-10 />10)$ & $110 / 56 / 49$ \\
\hline WBC $\left(\times 10^{9} / \mathrm{L}\right)(<4 / 4-10 />10)$ & $15 / 164 / 36$ \\
\hline Platelets $\left(\times 10^{9} / \mathrm{L}\right)(<150 / 150-450 />450)$ & $90 / 122 / 3$ \\
\hline Plasma cells $(\%)(<10 / 10-<20 / 20-<40 / \geq 40)$ & $22 / 48 / 53 / 92$ \\
\hline Calcium $(\mathrm{mg} / \mathrm{dL})(<8.5 / 8.5-10.5 />10.5)$ & $28 / 93 / 94$ \\
\hline Creatinine $(\mathrm{mg} / \mathrm{dL})(<0.9 / 0.9-1.3 />1.3)$ & $20 / 80 / 115$ \\
\hline Albumin $(\mathrm{g} / \mathrm{dL})(<3.5 / 3.5-5.2 />5.2)$ & $96 / 113 / 6$ \\
\hline$\beta 2$-microglobulin $(\mathrm{mg} / \mathrm{L})(<3.5 / 3.5-5.5 />5.5)$ & $48 / 40 / 127$ \\
\hline $\begin{array}{l}\text { Immunoglobulins (IgA/ IgG/ IgM/ M-band/ } \\
\text { LC) }\end{array}$ & $41 / 120 / 4 / 39 / 11$ \\
\hline ISS stage (I/ II/ III) & $38 / 34 / 143$ \\
\hline
\end{tabular}

* Retired; Daily laborer; Homemaker; Unemployed; Normal range - WBC 4-11 x10 $/ \mathrm{L}$; Hb 11-16 g/dL; Platelets $150-450 \times 10^{9} / \mathrm{L}$; Plasma cells 0-3.5\%; Calcium 8.5-10.5 mg/dL; Creatinine 0.9-1.3 mg/ $\mathrm{dL}$; Albumin 3.5-5.2 g/dL; $\beta 2$-microglobulin 1.1-2.4 mg/L. 
Table 2. Cytogenetic Aberrations Detected by Interphase FISH in 215 Multiple Myeloma Patients

\begin{tabular}{|c|c|c|}
\hline S. No. & FISH abnormality & Frequency $(\%)$ \\
\hline 1 & $\begin{array}{l}\text { Trisomy (ies) without } I G H \text { abnormality/ } \\
\text { monosomy } 13 / 13 \text { q deletion* }\end{array}$ & $48(22.3)$ \\
\hline \multirow[t]{5}{*}{2} & $\begin{array}{l}I G H \text { abnormality without trisomy (ies)/ } \\
\text { monosomy } 13 / 13 \text { q deletion }\end{array}$ & $14(6.5)$ \\
\hline & $\mathrm{t}(11 ; 14)$ & 7 \\
\hline & $\mathrm{t}(4 ; 14)$ & 3 \\
\hline & $\mathrm{t}(14 ; 16)$ & 2 \\
\hline & Unknown partner & 2 \\
\hline 3 & $\begin{array}{l}\text { Monosomy } 13 / 13 \mathrm{q} \text { deletion/ without } \\
\text { trisomy (ies)/ IGH abnormality } \dagger\end{array}$ & $10(4.7)$ \\
\hline \multirow[t]{5}{*}{4} & $I G H$ abnormality with trisomy (ies) & $25(11.6)$ \\
\hline & $\mathrm{t}(11 ; 14)$ & 4 \\
\hline & $t(4 ; 14)$ & 5 \\
\hline & $t(14 ; 16)$ & 7 \\
\hline & Unknown partner & 9 \\
\hline \multirow[t]{5}{*}{5} & $\begin{array}{l}I G H \text { abnormality with monosomy } 13 / \\
13 q \text { deletion }\end{array}$ & $27(12.6)$ \\
\hline & $\mathrm{t}(11 ; 14)$ & 3 \\
\hline & $\mathrm{t}(4 ; 14)$ & 20 \\
\hline & $\mathrm{t}(14 ; 16)$ & 1 \\
\hline & Unknown partner & 3 \\
\hline 6 & $\begin{array}{l}\text { Trisomy (ies) with monosomy } 13 / 13 q \\
\text { deletion }\end{array}$ & $23(10.7)$ \\
\hline \multirow[t]{5}{*}{7} & $\begin{array}{l}I G H \text { abnormality with trisomy (ies) and } \\
\text { monosomy } 13 / 13 \text { q deletion }\end{array}$ & $14(6.5)$ \\
\hline & $\mathrm{t}(11 ; 14)$ & 2 \\
\hline & $t(4 ; 14)$ & 4 \\
\hline & $t(14 ; 16)$ & 3 \\
\hline & Unknown partner & 5 \\
\hline 8 & Negative $^{\S}$ & $54(25.1)$ \\
\hline \multirow[t]{7}{*}{9} & \multicolumn{2}{|c|}{$\begin{array}{l}\text { Other abnormalities [in combination with above } \\
\text { aberrations] }\end{array}$} \\
\hline & TP53 deletion & 14 \\
\hline & Monosomy 14 (or $14 \mathrm{q} 32$ deletion) & 10 \\
\hline & Monosomy 16 (or $16 \mathrm{q} 23$ deletion) & 11 \\
\hline & Monosomy 4 (or 4 p16 deletion) & 7 \\
\hline & Monosomy 9 & 5 \\
\hline & Tetrasomy & 2 \\
\hline
\end{tabular}

*, a case with monosomy 14 included; $\uparrow$ cases with monosomy of 14

$13 / 13 q$ deletion in 27 cases, trisomy(ies) in 25 patients, and by both monosomy $13 / 13 \mathrm{q}$ deletion and trisomy(ies) in 14 cases (Table 2$)$. The $t(4 ; 14)(\mathrm{p} 16 ; \mathrm{q} 32)$ was the most common translocation seen in 32 patients $(14.9 \%)$. This was followed by $\mathrm{t}(11 ; 14)(\mathrm{q} 13 ; \mathrm{q} 32)$ in $16(7.4 \%)$ and $\mathrm{t}(14 ; 16)(\mathrm{q} 32 ; \mathrm{q} 23)$ in $13(6.1 \%)$ patients. Using the Cytocell LSI IGH/MYC probe it was found to be a complex translocation $\mathrm{t}(8 ; 14 ;$ ?) as only a single fusion signal was seen and the $14 \mathrm{q}$ segment was translocated on to an unknown chromosome (Figure 2a-d). All the four types of IGH translocations were relatively equally associated with gain of chromosomes while the translocation $\mathrm{t}(4 ; 14)$ was seen more frequently with monosomy 13/ deletion 13q (Table 2). Monosomy 13/
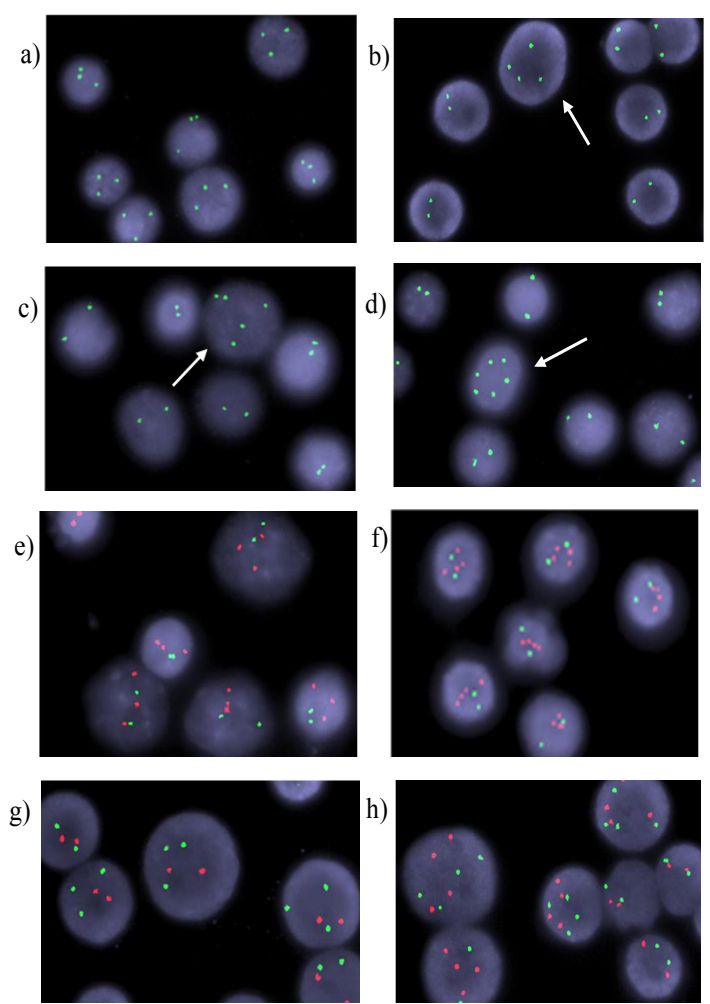

Figure 1. FISH Signal Patterns Illustrating Gain of Chromosomes. a, Trisomy 9 (3 green signals G3); b, Tetrasomy 9 (G4, arrow); c, Pentasomy (G5, arrow) and d, Hexasomy (G6, arrow) using CEP 9 probe; e, Trisomy 11 (3 orange signals O3) and f, Tetrasomy 11 (O4) with LSI IGH/CCND1 XT probe containing a mixture of CCND1 probe (11q13; orange) and IGH probe $(14 \mathrm{q} 32$; green), 2 green signals denote normal chromosome 14s; g, Trisomy 13 along with deletion 13q (two copies of locus 13q14.3 (O2) and three copies of $13 q 34$ (control, G3); and h, Tetrasomy 13 - G4O4 with LSI 13S319/13q34 probe.

deletion $13 \mathrm{q}$ was noted singly (4.7\%) (Figure $2 \mathrm{e}$ ) or as part of a complex karyotype in 74 patients (34.4\%).

Atypical FISH signals were observed in $21(9.8 \%)$ patients with an IGH rearrangement. The monoallelic deletion of 5' IGH involving the variable segment (IGHv) on the derivative chromosome 14 was found in $13 \mathrm{MM}$ patients (Figure $2 \mathrm{f}-\mathrm{g}$ ). The deletion of IGHv was biallelic in two cases as demonstrated by $\mathrm{O} 2$ pattern with IGH break apart probe (Figure $2 \mathrm{~h}$ ). The IGH translocation was $\mathrm{t}(11 ; 14)$ in seven cases, $\mathrm{t}(4 ; 14)$ in one, $\mathrm{t}(14 ; 16)$ in two, and an unknown partner in five cases. The deletion of IGHv on the native (or normal) chromosome 14 was seen in a single patient who also exhibited a cell line with the typical $\mathrm{t}(4 ; 14)$ translocation (without deletion) (Figure $3 a)$. Two cases, one with $t(4 ; 14)$ and the other with $t(14 ; ?)$ translocation exhibited a deletion of the 3 ' IGH constant segment on the derivative chromosome 14 (Figure 3b). It was of interest to observe the coexistence of IGH deletions with chromosomal gains in most of the cases. Five patients including two cases with $\mathrm{t}(11 ; 14)$, and one each with $\mathrm{t}(4 ; 14), \mathrm{t}(14 ; 16)$ and $\mathrm{t}(14 ; ?)$ showed monosomy 13/deletion 13q. Extra fusions were seen in three cases (two with $\mathrm{t}(4 ; 14)$ and one with $\mathrm{t}(14 ; 16))$, who also showed the classical fusion (Figure 3c-e).

Additional abnormalities including TP53 deletion, Asian Pacific Journal of Cancer Prevention, Vol 20 
Table 3. Comparison of Clinical Parameters in Myeloma Patients with Chromosome Abnormalities and iFISH Negative Patients

\begin{tabular}{|c|c|c|c|c|c|c|c|c|}
\hline $\begin{array}{l}\text { Cytogenetic abnor- } \\
\text { malities } \\
(\mathrm{N}=215)\end{array}$ & $\begin{array}{l}\text { Trisomies } \\
(\mathrm{N}=48)\end{array}$ & $\begin{array}{l}\text { IGHt only } \\
(\mathrm{N}=14)\end{array}$ & $\begin{array}{c}\text { Monosomy } \\
\text { 13/13q- } \\
(\mathrm{N}=10)\end{array}$ & $\begin{array}{l}\text { IGHt and } \\
\text { trisomies } \\
(\mathrm{N}=25)\end{array}$ & $\begin{array}{l}\text { IGHt and } \\
-13 / 13 q- \\
(\mathrm{N}=27)\end{array}$ & $\begin{array}{c}\text { IGHt and } \\
\text { trisomies and } \\
-13 / \mathrm{del}(13 \mathrm{q}) \\
(\mathrm{N}=14)\end{array}$ & $\begin{array}{c}\text { Trisomies and } \\
-13 / \operatorname{del}(13 q) \\
(\mathrm{N}=23)\end{array}$ & $\begin{array}{c}\text { FISH } \\
\text { Negative } \\
(\mathrm{N}=54)\end{array}$ \\
\hline Age (years) & $\begin{array}{c}60.5 \\
(54-66)\end{array}$ & $\begin{array}{c}56.5 \\
(44-63)\end{array}$ & $\begin{array}{c}50 \\
(48-58)\end{array}$ & $\begin{array}{c}60 \\
(51-64)\end{array}$ & $\begin{array}{c}54 \\
(49-68)\end{array}$ & $\begin{array}{c}59.5 \\
(49-72)\end{array}$ & $\begin{array}{c}59 \\
(51-66)\end{array}$ & $\begin{array}{c}57.5 \\
(50-65)\end{array}$ \\
\hline P-value & 0.34 & 0.17 & 0.12 & 0.87 & 0.61 & 0.51 & 0.95 & \\
\hline $\begin{array}{l}\text { Haemoglobin } \\
(\mathrm{g} / \mathrm{dL})\end{array}$ & $\begin{array}{c}8.3 \\
(7.4-9.9)\end{array}$ & $\begin{array}{c}8.9 \\
(6.9-9.4)\end{array}$ & $\begin{array}{c}8.8 \\
(7.72-9.4)\end{array}$ & $\begin{array}{c}7.8 \\
(6.5-9.2)\end{array}$ & $\begin{array}{c}7.9 \\
(7.15-8.8)\end{array}$ & $\begin{array}{c}8.4 \\
(7.5-9.1)\end{array}$ & $\begin{array}{c}8.2 \\
(6.9-9.4)\end{array}$ & $\begin{array}{c}9.35 \\
(7.9-10.8)\end{array}$ \\
\hline P-value & 0.049 & 0.02 & 0.22 & 0.01 & $<0.001$ & 0.49 & 0.02 & \\
\hline $\mathrm{WBC}\left(\times 10^{9} / \mathrm{L}\right)$ & $\begin{array}{c}5.7 \\
(4.9-8.3)\end{array}$ & $\begin{array}{c}5.2 \\
(4.9-6.4)\end{array}$ & $\begin{array}{c}8.44 \\
(6.07-10.77)\end{array}$ & $\begin{array}{c}7.3 \\
(5.2-8.2)\end{array}$ & $\begin{array}{c}6.9 \\
(5.46-9.47)\end{array}$ & $\begin{array}{c}6.01 \\
(4.27-7.33)\end{array}$ & $\begin{array}{c}5.5 \\
(4.4-9.5)\end{array}$ & $\begin{array}{c}7.21 \\
(5.7-9.2)\end{array}$ \\
\hline P-value & 0.93 & 0.26 & 0.23 & 0.31 & 0.23 & 0.14 & 0.5 & \\
\hline Platelets $\left(\times 10^{9} / \mathrm{L}\right)$ & $\begin{array}{c}158 \\
(127.3-239.3)\end{array}$ & $\begin{array}{c}126.5 \\
(116.8-173.5)\end{array}$ & $\begin{array}{c}189 \\
(116.25-232.5)\end{array}$ & $\begin{array}{c}157 \\
(124-206)\end{array}$ & $\begin{array}{c}151 \\
(110-196.5)\end{array}$ & $\begin{array}{c}153.5 \\
(87-223)\end{array}$ & $\begin{array}{c}164 \\
(142-232)\end{array}$ & $\begin{array}{c}168 \\
(132.8-253)\end{array}$ \\
\hline P-value & 0.34 & 0.01 & 0.62 & 0.31 & 0.15 & 0.34 & 0.44 & \\
\hline Plasma cells $(\%)$ & $\begin{array}{c}33.5 \\
(17.8-48.8)\end{array}$ & $\begin{array}{c}36 \\
(26.3-45.8)\end{array}$ & $\begin{array}{c}38 \\
(23.5-44.3)\end{array}$ & $\begin{array}{c}33 \\
(22-42)\end{array}$ & $\begin{array}{c}50 \\
(38.5-66)\end{array}$ & $\begin{array}{c}43.5 \\
(34.3-72.5)\end{array}$ & $\begin{array}{c}42 \\
(35-56)\end{array}$ & $\begin{array}{c}12 \\
(8.3-25)\end{array}$ \\
\hline P-value & $<0.001$ & 0.001 & 0.03 & $<0.001$ & $<0.001$ & 0.001 & $<0.001$ & \\
\hline Calcium (mg/dL) & $\begin{array}{c}10 \\
(9.1-10.9)\end{array}$ & $\begin{array}{c}10.45 \\
(9.27-10.87)\end{array}$ & $\begin{array}{c}10.15 \\
(8.67-10.5)\end{array}$ & $\begin{array}{c}10 \\
(8.9-10.5)\end{array}$ & $\begin{array}{c}10.9 \\
(9.4-11.5)\end{array}$ & $\begin{array}{c}10.1 \\
(8.72-10.95)\end{array}$ & $\begin{array}{c}10.1 \\
(8.9-10.9)\end{array}$ & $\begin{array}{l}9.15 \\
(8.5-10.1)\end{array}$ \\
\hline P-value & 0.01 & 0.38 & 0.24 & 0.4 & 0.02 & 0.16 & 0.92 & \\
\hline Creatinine (mg/dL) & $\begin{array}{c}1.57 \\
(1.1-2.4)\end{array}$ & $\begin{array}{c}1.2 \\
(0.9-1.7)\end{array}$ & $\begin{array}{c}1.95 \\
(1.1-4.3)\end{array}$ & $\begin{array}{c}1.4 \\
(1.1-2.2)\end{array}$ & $\begin{array}{c}2.1 \\
(1.3-3.3)\end{array}$ & $\begin{array}{c}1.25 \\
(1.1-1.7)\end{array}$ & $\begin{array}{c}1.7 \\
(1.3-2.5)\end{array}$ & $\begin{array}{c}1.23 \\
(0.9-2.1)\end{array}$ \\
\hline P-value & 0.91 & 0.94 & 0.32 & 0.88 & 0.13 & 0.04 & 0.45 & \\
\hline Albumin (g/dL) & $\begin{array}{c}3.45 \\
(3.1-4.1)\end{array}$ & $\begin{array}{c}3.45 \\
(3.1-4.3)\end{array}$ & $\begin{array}{c}3.45 \\
(3.3-4.1)\end{array}$ & $\begin{array}{c}3.5 \\
(3.2-3.9)\end{array}$ & $\begin{array}{c}3.1 \\
(2.8-3.5)\end{array}$ & $\begin{array}{c}3.75 \\
(3.2-3.9)\end{array}$ & $\begin{array}{c}3.8 \\
(3.4-4.4)\end{array}$ & $\begin{array}{c}3.8 \\
(3.2-4.3)\end{array}$ \\
\hline P-value & 0.37 & 0.62 & 0.68 & 0.96 & $<0.001$ & 0.51 & 0.88 & \\
\hline $\begin{array}{l}\text { ß2-microglobulin } \\
(\mathrm{mg} / \mathrm{L})\end{array}$ & $\begin{array}{c}6.45 \\
(3.17-8.35)\end{array}$ & $\begin{array}{c}5.05 \\
(3.27-9.17)\end{array}$ & $\begin{array}{c}6.2 \\
(4.45-10.77)\end{array}$ & $\begin{array}{c}7.1 \\
(5.2-15)\end{array}$ & $\begin{array}{c}7.9 \\
(5.7-13.5)\end{array}$ & $\begin{array}{c}7.4 \\
(6.57-11.87)\end{array}$ & $\begin{array}{c}9.2 \\
(5.55-12.75\end{array}$ & $\begin{array}{c}3.65 \\
(2.8-5.87)\end{array}$ \\
\hline P-value & 0.47 & 0.29 & 0.25 & 0.02 & 0.01 & 0.03 & 0.02 & \\
\hline
\end{tabular}

monosomy 14 (or $14 \mathrm{q}$ deletion), monosomy 16 (or $16 \mathrm{q} 23$ deletion), monosomy 4 (or 4p16 deletion) and monosomy 9 as part of a complex karyotype besides primary aberrations were noticed in $6.5 \%, 4.7 \%, 5.1 \%$, $3.3 \%, 2.3 \%$ and $0.9 \%$ of the patients respectively in this study. It is of interest to note that at least two of these abnormalities were present along with the primary abnormalities namely trisomy(ies) or IGH rearrangement or monosomy 13/deletion 13q suggestive of progressive disease in ten patients. TP53 deletion either because of $17 \mathrm{p}$ deletion or monosomy 17 was noticed as an additional abnormality in 14 patients. Clonal heterogeneity with at least 2 related clones was observed in 18.6\% (40/215) of the cases and all except three patients were in stage ISS III. Clonal evolution in the form of trisomy and tetrasomy of chromosomes 9,11 or 17 was noted in 31 patients. Two cases showed clones carrying monosomy 13 and deletion $13 \mathrm{q}$, and seven had both classical and atypical IGH translocations.

Comparable differences were noticed between patient group positive for abnormalities versus iFISH negative group. Patients with more than one type of abnormality were found to have significantly reduced hemoglobin $(\mathrm{Hb})$, higher percentage of plasma cells and higher B2microglobulin level (Table 3). Follow-up revealed $12 \mathrm{iFISH}$ negative patients to be in clinical remission at 20.5 months from diagnosis. Similarly, 14 patients belonging to the group trisomies only showed a longer median survival of 20.78 months. The median survival duration in IGH only $(n=3)$, IGH with trisomies $(n=7)$, IGH with monosomy $13 / 13 \mathrm{q}-(\mathrm{n}=6)$, and IGH with both abnormalities $(n=2)$ were $19.3,18.2,16$, and 16.5 months respectively. In contrast, the median survival in the two patients with $-13 / 13 q$ - and nine patients with trisomies and -13/13q- were 7 and 14.1 months respectively denoting a poor prognosis. These findings need to be validated over a larger sample size and longer survival duration.

\section{Discussion}

Multiple myeloma is a heterogeneous disease which is characterized by genomic alterations causing dysregulation of intracellular pathways and of importance in MM risk stratification. The clinical manifestations at presentation and a lower median age in comparison with that in developed nations were in accordance with published reports (Kumar et al., 2010). Interphase FISH enables a rapid identification of specific target regions frequently affected in $\mathrm{MM}$ in $50-90 \%$ of $\mathrm{MM}$ cases depending on the probes used (Fonseca et al., 2004; Avet-Loiseau et al., 2007; Kumar et al., 2012; Amare et al., 2016). Trisomy of at least one of the odd-numbered 

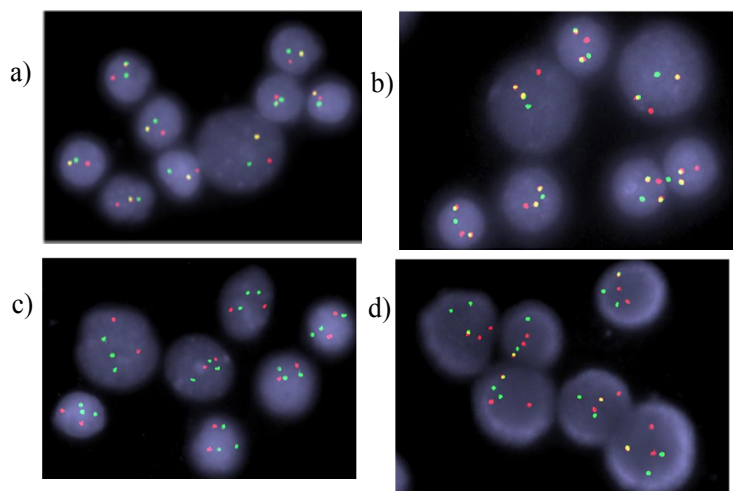

e)
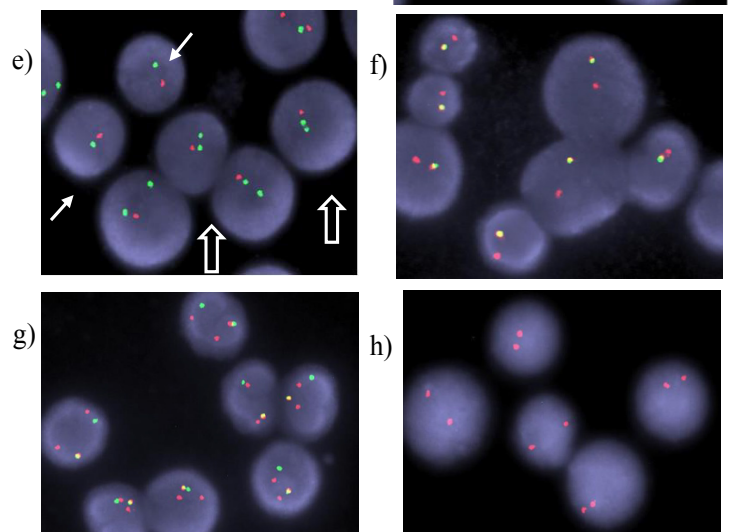

Figure 2. FISH Signals Demonstrating IGH Rearrangements; a, with IGH break-apart probe [IGH constant region (IGHc O1), IGH variable region (IGHv G1) and one yellow signal (fusion F1)]; b, with LSI IGH/ FGFR3 probe [G1 (IGH), O1 (FGFR3) and F2 showing $\mathrm{t}(4 ; 14)]$; c, IGH translocation involving an unidentified partner chromosome - one green signal on the normal chromosome 14 , one on the derivative 14 and one on the unknown chromosome - G3O2 indicating $\mathrm{t}(14 ; ?)$; , Complex t(8;14;?) translocation using LSI IGH/MYC probe $(\mathrm{F} 1 \mathrm{G} 2 \mathrm{O} 2)$; e, LSI 13S319/13q34 probe showing monoallelic deletion of locus $13 \mathrm{q} 14.3$ (O1) with two copies of locus 13q34 (control, G2, (open arrow) and monosomy 13 (G1O1) (solid arrow); Deletion of IGHv on derivative 14 with IGH break-apart probe (F1O1) (f); and with IGH/FGFR3 probe (F1G1O2) (g); h, Biallelic loss of IGHv with IGH break-apart probe $(\mathrm{O} 2)$.

chromosomes was observed in $42 \%$ patients using centromeric probes for three additional chromosomes 3 , 7 and 15 besides chromosome 9 (Rajan and Rajkumar 2015). In contrast only 48 patients (22.3\%) exhibited gain of chromosome(s) in this study. Trisomies which confer a good prognosis are the result of a single catastrophic mitotic event and are thought to increase the copy number of gene loci critical for tumor suppression or mediating drug sensitivity (Prideaux et al., 2014). However, the presence of trisomies together with translocations as seen in approximately $10 \%$ of patients could ameliorate the adverse outcome (Kumar et al., 2012). This effect could be seen in the few patients who were followed up.

The frequencies of the cytogenetically cryptic translocations $\mathrm{t}(4 ; 14)$ and $\mathrm{t}(14 ; 16)$ were in agreement with the reported frequency of $15-20 \%$ and $5-7 \%$ respectively (Moreau et al., 2002; Fonseca et al., 2004). However, the translocation $\mathrm{t}(11 ; 14)$ was found to occur at a lower frequency $(7.4 \%)$ in contrast to about $15 \%$ described in the literature (Fonseca et al., 2009; Prideaux et al., 2014; a)
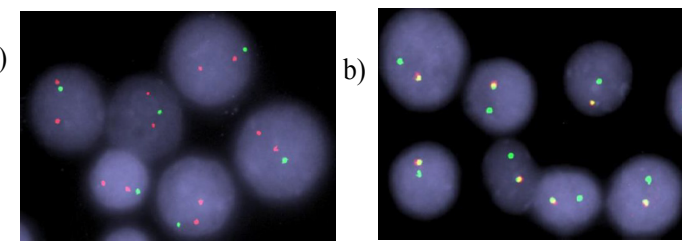

c)

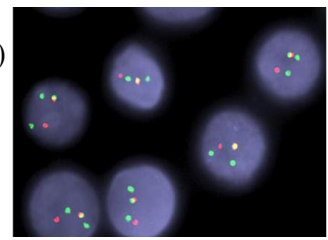

d)

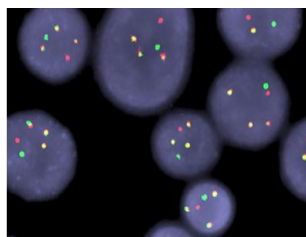

e)
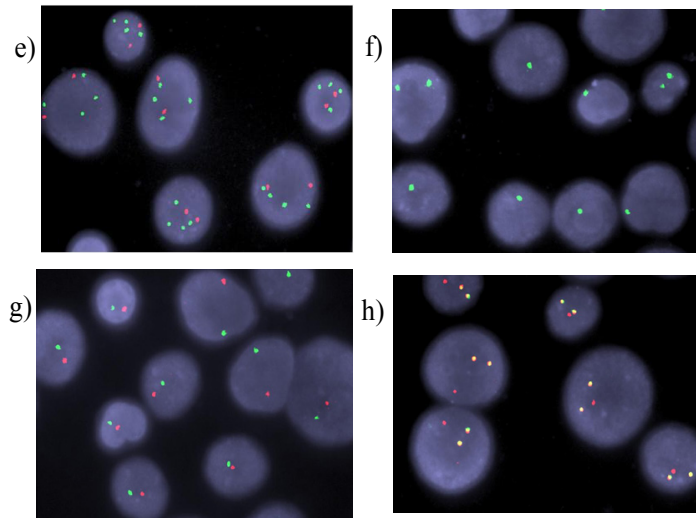

Figure 3. FISH Signals Representing IGH Rearrangements and Monosomies - IGH break-apart probe showing deletion of IGHv on normal chromosome 14 (G1O2) (a); and deletion of IGHc on derivative 14 (F1G1) (b); Gain of IGHv on derivative 14 illustrated with IGH-break apart probe (F1G2O1) (c); with Dual colour fusion probes (F3G1O1) (d); and when the 14q32 rearrangement involves an unidentified chromosome other than that specified by the dual fusion probe- G4O2 (e); CEP 9 Spectrum Green probe showing monosomy of chromosome 9 (G1) (f); Monosomy of normal chromosome 14 (or 14q32 deletion) shown with IGH break-apart probe (G1O1) (g) and fusion probes (F2O1) (h).

Talley et al., 2015). This finding could imply geographic heterogeneity with racial and ethnic diversity (Greenberg et al., 2015; Amare et al., 2016). A majority of the patients with $\mathrm{t}(4 ; 14)$ also exhibited monosomy $13 / 13 \mathrm{q}$ - as demonstrated earlier (Avert-Loiseau et al., 2002). The occurrence of only chromosome 13 abnormalities in a subset of patients suggests that this could also be an early event in MM pathogenesis. Chng et al., (2007) observed $-13 / 13 q$ - in about $40-50 \%$ of MGUS tumors and in $50 \%$ of MM tumors. It has been hypothesized that deletion of chromosome $13 q$ precedes the $t(4 ; 14)$ translocation in the pathogenesis of MM (Kalff and Spencer, 2012).

Interphase FISH also identified submicroscopic deletions adjacent to the breakpoints of rearrangements undetected by conventional cytogenetics. IGH gene deletions including monoallelic deletion of entire IGH locus, monoallelic deletions of variable (IGHv)/ constant (IGHc) regions and biallelic deletion of IGHv have been reported in 14-23\% of newly diagnosed patients with MM (Trakhtenbrot et al., 2010; Hwang et al., 2011; He et al., 2015; Smol and Daudignon, 2017). Atypical FISH signal patterns corresponding to deletion of the variable/ constant 
regions of the gene were observed in $8.4 \%$ of our patients $(n=18)$ in the present study. These monoallelic deletions of the IGH variable regions were suggested to be a result of the DNA loss that accompanied somatic V-D-J recombination as a physiological event, not as part of an oncogenic process of B-lineage cells (Wlodarska et al., 2007). In most cases, IGHv deletions were on the normal chromosome 14 (Wlodarska et al., 2007; Hwang et al., 2011). However, the rearranged chromosome 14 was involved in IGH deletions in 15 cases and the normal chromosome 14 in only a single case in the present study.

The IGH deletions were reported to most often coexist with $13 q$ deletions in patients with MM (Trakhtenbrot et al., 2010; Hwang et al., 2011; He et al., 2015). Further, IGH deletions with the $\mathrm{t}(11 ; 14)$ were found only in MM cases with $13 \mathrm{q}$ deletion, while those $\mathrm{t}(11 ; 14)$-positive cases without any IGH deletions exhibited normal 13q (Trakhtenbrot et al., 2010; Hwang et al. 2011). In contrast, He et al., (2015) observed an increased incidence of IGH deletions in patients with $13 \mathrm{q}$ deletion and without $\mathrm{t}(4 ; 14)$. No such association was observed in this study. The patients carrying IGH deletion showed better overall response rate to induction therapy with bortezomib, epirubicin and dexamethasone but the deletion did not influence prognosis (He et al., 2015). Longitudinal studies in larger cohorts are needed to determine the significance of IGH deletions on prognosis of our MM patients.

Additional abnormalities, namely TP53 deletion and monosomies of chromosomes 4, 9, 14 and 16 were observed in $35(16.3 \%)$ patients in this study. The occurrence of cytogenetic abnormalities such as deletions involving chromosome $17 \mathrm{p}$ are typically considered as late events and are suggestive of clonal evolution and disease progression (Rajkumar et al., 2013; Jian et al., 2016). Patients with MM with sole translocation $t(11 ; 14)$ were found to have better overall survival (OS) when compared with patients with translocation $\mathrm{t}(11 ; 14)$ combined with the aberrations $\operatorname{del}(1 p), \operatorname{del}(13 q), \operatorname{del}(17 p)$, multiple gains(1q) and del(IGH) (Leiba et al., 2016). A brief follow-up for a period of about two years from the time of initial diagnosis revealed that the patients who exhibited a normal or gain of chromosomes FISH pattern showed improved survival while chromosome 13 abnormalities were an adverse prognostic factor. Further studies are needed to validate the clinical significance of IGH rearrangements especially IGH deletions and abnormalities of chromosome 1 (deletion of $1 \mathrm{p}$ and multiple gains of 1q) in multiple myeloma.

In conclusion, this study has demonstrated the importance of interphase FISH analysis in the identification of prognostically significant abnormalities for the implementation of stratified treatment approaches in the management of myeloma patients. Further investigations on geographically diverse populations with long-term follow-up would enable data comparison to confirm ethnic disparity.

\section{Statement conflict of Interest}

No relevant conflicts of interest to declare.

\section{References}

Amare PSK, Jain H, Nikalje S, et al (2016). Observation on frequency and clinico-pathological significance of various cytogenetic risk groups in multiple myeloma: an experience from India. Indian J Med Res, 144, 536-43.

Ashok V, Ranganathan R, Chander S, et al (2017). Comparison of diagnostic yield of a FISH panel against conventional cytogenetic studies for hematological malignancies: A South Indian Referral Laboratory Analysis Of 201 Cases. Asian Pac J Cancer Prev, 18, 3457-64.

Avet-Loiseau H, Facon T, Grosbois B, et al (2002). Intergroupe Francophone du Myélome. Oncogenesis of multiple myeloma: $14 \mathrm{q} 32$ and $13 \mathrm{q}$ chromosomal abnormalities are not randomly distributed, but correlate with natural history, immunological features, and clinical presentation. Blood, 99, 2185-91.

Avet-Loiseau H, Attal M, Moreau P, et al (2007). Genetic abnormalities and survival in multiple myeloma: the experience of the Intergroupe Francophone du Myélome. Blood, 109, 3489-95.

Bergsagel PL, Kuehl WM (2005). Molecular pathogenesis and a consequent classification of multiple myeloma. J Clin Oncol, 23, 6333-8.

Chng WJ, Glebov O, Bergsagel PL, Kuehl WM (2007) Genetic events in the pathogenesis of multiple myeloma. Best Pract Res Clin Haematol, 20, 571-96.

Fairfield H, Falank C, Avery L, Reagan MR (2016). Multiple myeloma in the marrow: pathogenesis and treatments. Ann N Y Acad Sci, 1364, 32-51.

Fonseca R, Barlogie B, Bataille R, et al (2004). Genetics and cytogenetics of multiple myeloma: a workshop report. Cancer Res, 64, 1546-58.

Fonseca R, Bergsagel PL, Drach J, et al (2009). International myeloma working group. International myeloma working group molecular classification of multiple myeloma: spotlight review. Leukemia, 23, 2210-21.

Greenberg AJ, Philip S, Paner A, et al (2015) Racial differences in primary cytogenetic abnormalities in multiple myeloma: a multi-center study. Blood Cancer J, 5, e271.

Greipp PR, San MJ, Durie BG, et al (2005). International staging system for multiple myeloma. J Clin Oncol, 23, 3412-20.

Gutiérrez NC, Castellanos MV, Martín ML, et al (2007) Prognostic and biological implications of genetic abnormalities in multiple myeloma undergoing autologous stem cell transplantation: $t(4 ; 14)$ is the most relevant adverse prognostic factor, whereas RB deletion as a unique abnormality is not associated with adverse prognosis. Leukemia, 21, 143-50.

Hanbali A, Hassanein M, Rasheed W, Aljurf M, Alsharif F (2017). The evolution of prognostic factors in multiple myeloma. Adv Hematol, 2017, Article ID 4812637, 11 pages, 2017. https://doi.org/10.1155/2017/4812637.

$\mathrm{He} \mathrm{H}, \mathrm{Fu} \mathrm{W}$, Jiang H, et al (2015). The clinical characteristics and prognosis of IGH deletion in multiple myeloma. Leuk Res, 39, 515-9.

Hwang Y, Lee JY, Mun YC, et al (2011). Various patterns of IgH deletion identified by FISH using combined $\operatorname{IgH}$ and IgH/CCND1 probes in multiple myeloma and chronic lymphocytic leukemia. Int J Lab Hematol, 33, 299-304.

Jian Y, Chen X, Zhou H, et al (2016) Prognostic impact of cytogenetic abnormalities in multiple myeloma. Medicine, 95, e3521.

Kalff A, Spencer A (2012). The t(4;14) translocation and FGFR3 overexpression in multiple myeloma: prognostic implications and current clinical strategies. Blood Cancer J, 2, e89. 
Kumar L, Verma R, Radhakrishnan (2010). Recent advances in the management of multiple myeloma. Natl Med J India, 23, 210-8.

Kumar S, Fonseca R, Ketterling RP, et al (2012). Trisomies in multiple myeloma: impact on survival in patients with high-risk cytogenetics. Blood, 119, 2100-5.

Leiba M, Duek A, Amariglio N, et al (2016). Translocation $\mathrm{t}(11 ; 14)$ in newly diagnosed patients with multiple myeloma: Is it always favorable?. Genes Chromosomes Cancer, 55, 710-8.

Li S, Lim H-H, Woo K-S, Kim S-H, Han J-Y (2016). A retrospective analysis of cytogenetic alterations in patients with newly diagnosed multiple myeloma: a single center study in Korea. Blood Res, 51, 122-6.

Moreau P, Facon T, Leleu X, et al (2002). Recurrent 14q32 translocations determine the prognosis of multiple myeloma, especially in patients receiving intensive chemotherapy. Blood, 100, 1579-83.

Nadiminti K, Zhan F, Tricot G (2013). Cytogenetics and chromosomal abnormalities in multiple myeloma - A review. Clon Transgen, 2, 114.

Nilsson T, Höglund M, Lenhoff S, et al (2003). A pooled analysis of karyotypic patterns, breakpoints and imbalances in 783 cytogenetically abnormal multiple myelomas reveals frequently involved chromosome segments as well as significant age- and sex-related differences. Br J Haematol, 120, 960-9.

Palumbo A, Avet-Loiseau, Oliva S, et al (2015). Revised International Staging System for multiple myeloma: A report from International Myeloma Working Group. J Clin Oncol, 33, 2863-9.

Prideaux SM, O’Brien EC, Chevassut TJ (2014). The genetic architecture of multiple myeloma. Adv Hematol, 2014, Article ID 864058, 16 pages, 2014. https://doi. org $/ 10.1155 / 2014 / 864058$.

Rajan AM, Rajkumar SV (2015). Interpretation of cytogenetic results in multiple myeloma for clinical practice. Blood Cancer J, 5, e365.

Rajkumar SV, Gupta V, Fonseca R, et al (2013). Impact of primary molecular cytogenetic abnormalities and risk of progression in smoldering multiple myeloma. Leukemia, 27, 1738-44.

Rajkumar SV, Dimopulos, Palumbo, et al (2014). International Myeloma Working Group updated criteria for the diagnosis of multiple myeloma. Lancet Oncol, 15, e538-48.

Rajkumar SV, Kumar S (2016). Multiple myeloma: Diagnosis and treatment. Mayo Clin Proc, 9, 101-19.

Smol T, Daudignon A (2017). Comparison of IGH profile signals using $\mathrm{t}(4 ; 14)$ and IGH Break-apart probes by FISH in multiple myeloma. Cytogenet Genome Res, 153, 18-21.

Sommaluan S, Rerkamnuaychoke, Pauwilai T, et al (2017). The utilization of karyotyping, iFISH, and MLPA for the detection of recurrence genetic aberrations in multiple myeloma. Asian Pac J Cancer Prev, 18, 3135-42.

Talley PJ, Chantry AD, Buckle CH (2015). Genetics in myeloma: genetic technologies and their application to screening approaches in myeloma. Br Med Bull, 113, 15-30.

Trakhtenbrot L, Hardan I, Koren-Michowitz M, et al (2010). Correlation between losses of IGH or its segments and deletions of 13q14 in $\mathrm{t}(11 ; 14)$ (q13; q32) multiple myeloma. Genes Chromosomes Cancer, 49, 17-27.

Wlodarska I, Matthews C, Veyt E, et al (2007). Telomeric IGH losses detectable by fluorescence in situ hybridization in chronic lymphocytic leukemia reflect somatic $\mathrm{VH}$ recombination events. J Mol Diagn, 9, 47-54.

Yuvegir OO, Sahin FI, Yilmaz Z, et al (2009). Fluorescent in situ hybridization studies in multiple myeloma. Hematology,
$14,90-4$.

Cytogenetic Abnormalities in Myeloma

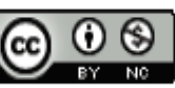

This work is licensed under a Creative Commons AttributionNon Commercial 4.0 International License. 